\title{
Increased Levels of Inflammatory Marker hsCRP, MDA and Lipid Profile in Non-obese Hypertension Subjects
}

\author{
Nakkeeran $\mathbf{M}^{1}$, Periasamy $\mathbf{S}^{2}$, Inmozhi $\mathbf{S R}^{1^{*}}$, Santha $\mathbf{K}^{1}$ and Sethupathy $\mathbf{S}^{1}$
}

${ }^{1}$ Department of Biochemistry, Rajah Muthiah Medical College, Annamalai University, Tamilnadu, India

${ }^{2}$ Department of General Medicine, Rajah Muthiah Medical College and Hospital, Annamalai University, Tamilnadu, India

*Corresponding author: Inmozhi SR, Department of Biochemistry, Rajah Muthiah Medical College, Annamalai University, Tamilnadu, India, Tel: 04144 238 282; E-mail: dr.inmozhi@gmail.com

Received date: September 12, 2017; Accepted date: October 10, 2017; Published date: October 19, 2017

Copyright: @ 2017 Inmozhi SR, et al. This is an open-access article distributed under the terms of the Creative Commons Attribution License, which permits unrestricted use, distribution, and reproduction in any medium, provided the original author and source are credited.

\begin{abstract}
Introduction: High sensitive C-reactive protein (hsCRP) is a very sensitive marker of inflammation, which is synthesized in the liver and has been a widely used biomarker for risk stratifying in Cardio vascular disease (CVD). It is positively correlated with abdominal fat and closely correlated with increased risk of cardiovascular events and obesity had the predominant association with cytokine levels. Obesity induces systemic oxidative stress and causes dysregulation of adipo cytokines and development of metabolic syndrome. In our study, we investigated hsCRP levels in non-obese hypertensive subjects on treatment and its relationship with oxidative stress and lipid profile.

Methods: Patients with secondary hypertension, past history of stroke, coronary artery disease, myocardial infarction, and diabetes mellitus were excluded. Serum lipid profile and thiobarbituric acid reactive substances, hsCRP were estimated in these patients by standard procedures and the values were compared with healthy controls. Totally 160 subjects were included in the study. 115 were considered as Hypertension with blood pressure $>140 / 90 \mathrm{mmHg}$ and 45 as healthy controls after obtaining consent.
\end{abstract}

Results: There is significant difference in hsCRP levels between study groups, and hsCRP levels correlate with blood pressure. The level of MDA and hsCRP levels were significantly increased in hypertensive subjects compared to control group.

Conclusion: Our study shows that even in non-obese hypertensive subjects there was significant increase of hsCRP, LDL Cholesterol. Hence elevated hsCRP levels in addition to lipid profile screening may be a valuable tool for prediction of CVD risk in hypertensive subjects.

Keywords: Hypertension; Malondialdehyde (MDA); High sensitivity $\mathrm{C}$ reactive protein (hsCRP); Cardio vascular disease (CVD)

\section{Introduction}

The leading cause of mortality and morbidity all over the world is Cardiovascular diseases (CVDs), including India [1]. According to World Health Organization (WHO) estimates, 17.3 million people died from CVDs in 2008, represented $30 \%$ of all global deaths. Of these deaths, an estimated 7.3 million were due to CHD and 6.2 million were due to stroke [2]. In developing countries, rates are predicted to increase by $120 \%$ in women and $137 \%$ in men from 1990 to 2020 [3]. In consideration of the important role that inflammatory processes play in determining plaque stability, recent studies have focused on whether biomarkers of inflammation may help to improve risk stratification and identify patient groups who might get benefit from particular treatment strategies. Among them, C-reactive protein (CRP), a prototype marker of the inflammatory process, is the most studied both as a causal factor and in the prediction of CHD [4]. Multiple prospective cohort studies have shown the association between increased CRP levels and increased CVD event risk in patients with established disease, and the incidence of first cardiovascular events in individuals at risk for atherosclerosis [5]. hsCRP testing valuable in both, primary and secondary CVD prophylaxis. And for those, who already suffer from CVD, this test is useful in evaluation of disease severity, treatment efficacy and outcome prognosis [6-8]. Lifestyle changes and medications can lower blood pressure and decrease the risk of health complications [9]. Lifestyle changes include weight loss, decreased salt intake, physical exercise, and a healthy diet [10]. Elevated blood pressure in pre hypertensive stage is considered as a risk factor for increasing cardiovascular diseases [11]. Oxidative stress can occurs when there is an imbalance between the generation of reactive oxygen species (ROS) and the antioxidant defense systems and it may shows evidence that can induce hypertension [12].

\section{C-reactive protein (CRP)}

CRP belongs to the pentraxin family of calcium dependent ligandbinding plasma proteins. The protomers are non-covalently associated in an annular configuration with cyclic pentameric symmetry (Figure 1) [13]. Early clues states that inflammatory biomarker might be linked to atherothrombosis are evident in 2 case reports presented by Gunnar Lofstrom from the State Bacteriologic Laboratory in Stockholm in 1943, in which increases in CRP following AMI was described [14]. In human, the CRP gene is located on chromosome 1q23, in a conserved genetic region, which codes for proteins important for immune system as well as cell to cell communication [15]. The major part of the CRP 
Citation: Nakkeeran M, Priasamy S, Inmozhi SR, Santha K, Sethupathy S (2017) Increased Levels of Inflammatory Marker hsCRP, MDA and Lipid Profile in Non-obese Hypertension Subjects. Biochem Anal Biochem 6: 339. doi:10.4172/2161-1009.1000339

Page 2 of 4

present in the plasma comes from the liver, where the synthesis of CRP is mainly regulated by interleukin-6 (IL-6), which in turn is upregulated by other inflammatorycytokines such as IL-1 and tumor necrosis factor alpha (TNF-) [16].

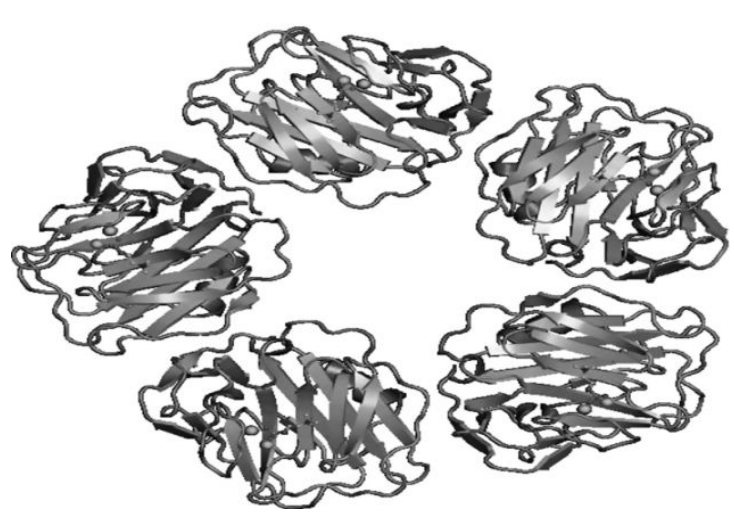

Figure 1: Pentameric structure of CRP.

\section{Inflammation and CRP}

The pro-atherogenic effects of CRP extend beyond the endothelium to the vascular smooth muscle. CRP plays a pivotal role in many aspects of atherogenesis as described briefly below (Figure 2): CRP increases LDL uptake into macrophages and enhances the ability of macrophages to form foam cells. It also binds the phosphocholine of oxidized LDL. CRP inhibits endothelial NO synthase expression in ECs. NO has important anti-atherogenic effects, including decreased platelet aggregation, vasoconstriction, and smooth muscle cell proliferation. CRP upregulates the expression of adhesion molecules in ECs that can attract monocytes to the site of injury [17].

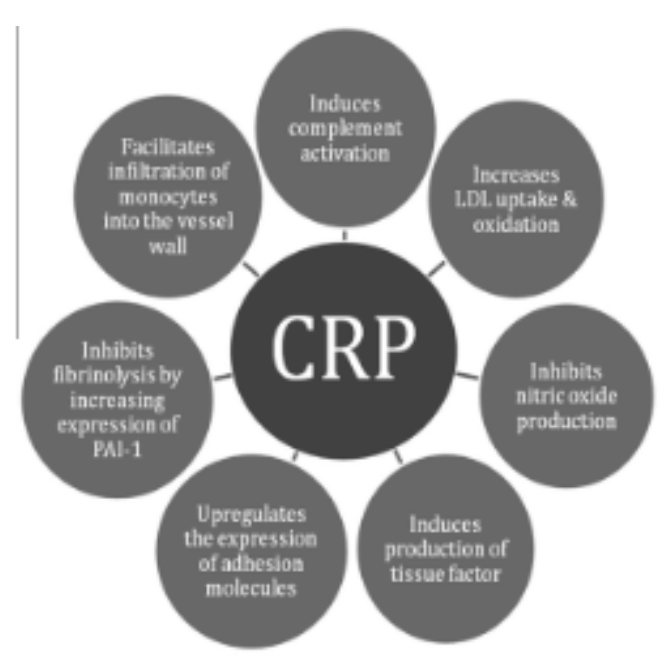

Figure 2 Representation of CRP-mediated effects on atherosclerosis and CHD.

In case of chronic low-intensity inflammation CRP damages the glycocalyx of vascular endothelium, causing its Dysfunction and making it more susceptible to proatherogenic factors [18].

\section{Methods and Materials}

This prospective study was carried out in the Department of Biochemistry, Rajah Muthiah Medical College and Hospital, Annamalai University. A volume of $5 \mathrm{ml}$ of fasting venous blood sample was collected in Clot activator tube with aseptic precautions and serum were separated, aliquoted and kept at $-20^{\circ} \mathrm{C}$ for testing. 115 subjects of both male and female age group between 35-55 years were included in the study as a test group with Essential Hypertension of blood pressure $140 / 90 \mathrm{mmHg}$ and 45 subjects were considered as healthy subjects with normal blood pressure 120/80 mmHg. Patients with secondary hypertension, past history of stroke, coronary artery disease (CAD), myocardial infarction, and peripheral vascular disease and diabetes mellitus were excluded. Serum lipid profile, plasma total antioxidant status (TAS) and serum thiobarbituric acid reactive substances (STBARS) hsCRP were estimated in these patients by standard procedures and the values were compared with healthy control subjects. Separated serum was used to analyze lipid profile, uric acid, Malondialdehyde (MDA), hsCRP were estimated in these patients by standard procedures and the values were compared with healthy control subjects. Total cholesterol, high density lipoprotein cholesterol (HDL-C), Triglyceride (TG), was estimated using Erba assay kits. Low density lipoprotein cholesterol (LDL-C) was calculated by Freidewalds formula. Very low density lipoprotein cholesterol (VLDL-C) was calculated by formula TG/5. MDA was measured using thio-barbituric acid (TBA). The mixture was heated at $100^{\circ} \mathrm{C}$ for $15 \mathrm{~min}$, allowed to cool and centrifuged at $5000 \mathrm{rpm}$. Total anti-oxidant status was assayed by measuring FRAP (ferric reducing activity of plasma).

\begin{tabular}{|l|l|l|l|}
\hline Variables & Test group & Control group & P value \\
\hline Age in years & $49.33 \pm 10.01$ & $50.71 \pm 10.06$ & 0.499 \\
\hline FBS $(\mathrm{mg} / \mathrm{dl})$ & $91.30 \pm 9.22$ & $86.66 \pm 5.83$ & 0.002 \\
\hline SBP $(\mathrm{mmHg})$ & $158.15 \pm 10.46$ & $121.39 \pm 8.03$ & 0.001 \\
\hline DBP $(\mathrm{mmHg})$ & $102.15 \pm 6.16$ & $81.08 \pm 4.70$ & 0.001 \\
\hline Triglycerides $(\mathrm{mg} / \mathrm{dl})$ & $126.97 \pm 29.29$ & $111.78 \pm 23.91$ & 0.002 \\
\hline Total cholesterol $(\mathrm{mg} / \mathrm{dl})$ & $189.71 \pm 25.99$ & $175.95 \pm 23.42$ & 0.002 \\
\hline HDL $(\mathrm{mg} / \mathrm{dl})$ & $43.73 \pm 2.79$ & $54.34 \pm 4.72$ & 0.004 \\
\hline LDL $(\mathrm{mg} / \mathrm{dl})$ & $89.28 \pm 19.90$ & $81.83 \pm 13.51$ & 0.022 \\
\hline MDA $(\mathrm{mM} / \mathrm{L})$ & $13.36 \pm 1.77$ & $14.06 \pm 1.82$ & 0.026 \\
\hline hsCRP & $3.86 \pm 1.04$ & $3.42 \pm 0.63$ & 0.008 \\
\hline
\end{tabular}

Table 1: Comparison of study variables in test and control groups.

\begin{tabular}{|l|l|l|}
\hline Variables & r value & P value \\
\hline CHO & 0.31 & 0.002 \\
\hline TG & 0.1 & 0.002 \\
\hline HDL & 0.22 & 0.004 \\
\hline LDL & 0.35 & 0.022 \\
\hline
\end{tabular}

Table 2: correlation of hsCRP with serum lipid profile. 
At lower $\mathrm{pH}$, reduction of a ferric tripyridyltriazine complex to a ferrous form produces an intense blue color, which is measured at 593 nm. Statistical software: Fischer exact test with Yates correction has been used to find out the significance $(\mathrm{p}=0.05)$ for small number of samples for various parameters among cases and controls (Tables 1 and 2).

\section{Results}

This prospective study was carried out in the Department of Biochemistry, Rajah Muthiah Medical College and Hospital, Annamalai University. A volume of $5 \mathrm{ml}$ of fasting venous blood sample was collected in Clot activator tube with aseptic precautions and serum were separated, aliquot and kept at $-20^{\circ} \mathrm{C}$ for testing. 120 subjects of both male and female age group between 35-55 years were included in the study as a test group with Essential Hypertension of blood pressure $140 / 90 \mathrm{mmHg}$ and 45 subjects were considered as healthy subjects with normal blood pressure 120/80 mmHg. Patients with obesity, secondary cause of hypertension, past history of stroke, coronary artery disease (CAD), myocardial infarction, and peripheral vascular disease and diabetes mellitus were excluded. Serum lipid profile, plasma total antioxidant status (TAS) and serum thiobarbituric acid reactive substances (STBARS)hsCRP were estimated in these patients by standard procedures and the values were compared with healthy control subjects. Separated serum was used to analyze lipid profile, Malondialdehyde (MDA), Total antioxidant status (TAS) and serum thiobarbituric acid reactive substances (STBARS) hsCRP were estimated in these patients by standard procedures and the values were compared with healthy control subjects. Total cholesterol, high density lipoprotein cholesterol (HDL-C), Triglyceride (TG), was estimated using Erba assay kits. Low density lipoprotein cholesterol (LDL-C) was calculated by Freide walds formula. Very low density lipoprotein cholesterol (VLDL-C) was calculated by formula TG/5. MDA was measured using thiobarbituric acid (TBA). The mixture was heated at $100 \mathrm{C}$ for $15 \mathrm{~min}$, allowed to cool and centrifuged at $5000 \mathrm{rpm}$. Total anti-oxidant status was assayed by measuring FRAP (ferric reducing activity of plasma). At lower $\mathrm{pH}$, reduction of a ferric tripyridyltriazine complex to a ferrous form produces an intense blue color, which is measured at $593 \mathrm{~nm}$.

\section{Statistical software}

Fischer exact test with Yates correction has been used to find out the significance $(p=0.05)$ for small number of samples for various parameters among cases and controls.

\section{Discussion}

Our data clearly show that significant increase in Total Cholesterol, Triglyceride, LDL-C, MDA, CRP, whereas HDL-C, antioxidants, were decreased among hypertensive compared to controls, marking ongoing oxidative stress in hypertensive patients. An association between sustained high values of CRP following AMI and adverse outcomes was first reported in 1982 [18]. The higher the maximum CRP recorded, the more severe the infarction suffered, the greater the likelihood of ventricular remodeling, the lower the ejection fraction, and the greater the risk of heart failure, heart rupture, and death [19]. Currently, anti-inflammatory drugs (methotrexate and IL-1b inhibitorcanakinumab), which do not affect CRP or LDL cholesterol concentration, are being investigated. And if they proved to be effective, it would support the theory that atherosclerosis has an inflammatory Origin [20]. Thus a practical definition ohypertension is the level of BP at which the benefits of treatment towards the significance of the costs anhazards' [21] Oxidative stress because of excessive production of ROS outstripping antioxidant defense mechanism has been implicated in many pathophysiological conditions that affect the cardiovascular system, such as hypercholesterolemia, diabetes, and hypertension [22,23]. Some of studies refers that high sensitive C-reactive protein ( $\mathrm{HsCPR}$ ) has a role in development of hypertension [24]. CRP is an acute phase protein which is increased in plasma during inflammation. Many crosssectional studies show increased CRP level in hypertensive people [25-27]. Many studies show the difference in the elevation levels of hsCRP was also found to be duration dependent Patients with shorter duration of hypertensive history were found to have significantly elevated levels of hs-CRP compared to those with longer duration of hypertensive history $[28,29]$. Obesity is closely associated with metabolic syndrome including hyperglycemia, dyslipidemia and hypertension. Obesity induces systemic oxidative stress and that increased oxidative stress in accumulated fat is, the underlying cause of dysregulations of adipocytokines and development of metabolic syndrome $[30,31]$. In our study there is a difference significant between the study group with non-obese subjects.

\section{Conclusion}

Our study shows that significant increase in LDL Cholesterol and high sensitive C-reactive protein may lead to cause risk of Cardio Vascular Disease and atherosclerosis etc., Elevated hsCRP levels in addition to lipid profile screening may be a valuable tool to predict future CVD risk. So estimation of serum hsCRP can be a good marker in diagnosing hypertensive and prevent the occurrence of hypertension and cardio vascular disorders in future. Non-obesity is not closely associated with hypertension there will be mild association, specific reason and more study is need to identify.

\section{References}

1. Gupta R, Joshi P, Mohan V, Reddy KS, Yusuf S (2008) Epidemiology and causation of coronary heart disease and stroke in India. Heart 94: 16-26.

2. World Health Organization (2011) Global atlas on cardiovascular disease prevention and control. Geneva, Switzerland.

3. Murray CJL, lopez AD (1997) alternative projections of mortality and disability by cause 1990-2020: global burden of disease study. Lancet 349 : 1498-504.

4. Calabro P, Golia E, Yeh ET (2012) Role of C-reactive protein in acute myocardial infarction and stroke: possible therapeutic approaches. Curr Pharm Biotechnol 13: 4-16.

5. Greenland P, Alpert JS, Beller GA, Benjamin EJ, Budoff MJ, et al. (2010) Cardiovasc Electrophysiol 21: 1064-1070.

6. ACCF/AHA (2010) Guideline for, assessment cardiovascular risk in asymptomatic adults: executive summary: a report of the American College of Cardiology Foundation/American Heart Association Task Force on Practice Guidelines. Circulation 122: 2748-2764.

7. Salazar J, Martinez MS, Mervin CM, Toledo A, Anez R, et al. (2014) Creactive protein clinical and epidemiological perspectives. Cardiol,Res,Pract 2014: 605810.

8. Araujo JP, Lourenc P, Zevedo A, Friores F, Rocha-Goncalves F, et al. (2009) Prognostic value of high-sensitivity C-reactive protein in heart failure: a systematic review. J Cardiac Fail 15: 256-266.

9. Alyan O, Metin F, Kacmaz F, Ozdemir O, Maden O, et al. (2009) High levels of high sensitivity C-reactive protein predict the progression of chronic rheumatic mitral stenosis. J Thromb Thrombolysis 28: 63-69. 
Citation: Nakkeeran M, Priasamy S, Inmozhi SR, Santha K, Sethupathy S (2017) Increased Levels of Inflammatory Marker hsCRP, MDA and Lipid Profile in Non-obese Hypertension Subjects. Biochem Anal Biochem 6: 339. doi:10.4172/2161-1009.1000339

Page 4 of 4

10. National heart, lung, and blood institute (2016) How is high blood pressure treated?.

11. Poulter NR, Prabhakaran D, Caulfield M (2015) "Hypertension". Lancet 386: 801-812.

12. King DE, Egan BM, Mainous AG, Geesey ME (2004) Elevation of creactive protein in people with prehypertension. J clinhypertens 6 : $562-568$.

13. Becker LB (2004) New concepts in reactive oxygen species and cardiovascular reperfusion physiology Cardiovascular res. Gen physiol biophys 61: 461-470.

14. http://en.wikipedia.org/wiki/C-reactive_protein

15. Lofstrom G (1943) Nonspecific capsular swelling in pneumococci aseriologic and clinical study. Acta Med Scand Suppl 141: 3-98.

16. Bucova M, Bernadic M, Buckingham T (2008) C-reactive protein cytokines and inflammation in cardiovascular diseases. Bratisl Lek Listy 109: 333-340.

17. Paffen E, DeMaat MP (2006) C-reactive protein in atherosclerosis: a causal factor? Cardiovasc Res 71: 30-39.

18. Pfutzner A, Schondorf T, Hanefeld M, Forst T (2010) High-sensitivity Creactive protein predicts cardiovascular risk in diabetic and nondiabetic patients: effects of insulin-sensitizing treatment with pioglitazone. I Diabetes Sci Technol 4: 706-716.

19. de Beer FC, Hind CRK, Fox KM, Allan R, Maseri A, et al. (1982) Measurement of serum C-reactive protein concentration in myocardial ischaemia and infarction. Br Heart J 47: 239-243.

20. Habib SS, Kurdi MI, Aseri ZA, Suriya MO (2011) CRP levels are higher in patients with ST elevation than non-ST elevation acute coronary syndrome. Arq Bras Cardiol 961: 13-17.

21. Calabro P, Golia E, Yeh ETH (2012) Role of C-reactive protein in acute myocardial infarction and stroke: possible therapeutic approaches. Curr Pharm Biotechnol 13: 4-16.
22. Kumara SN, Hemalatha, Sheethal KC, Shwetha, Rashmi TM (2013) Antioxidant status, oxidative stress and lipid profile in essential hypertensive men. Journal of evolution of medical and dental sciences 2: 2950.

23. Subash P, Gurumurthy P, Sarasabharathi A, Cherian KM (2010) Urinary 8-ohdg a marker of oxidative stress to dna and total antioxidant status in essential hypertension with south indian population. Indian journal of clinical biochemistry 25: 127-132.

24. Chisolm GM, Steinberg D (2000) The oxidative modification hypothesis of atherogenesis: an overview. Free radic biol med 28: 1815-1826.

25. Sung KC, Suh JY, Kim BS, Kang JH, Kim H, et al. (2003) High sensitivity C-reactive protein as an independent risk factor for essential hypertension. Am J Hypertension 16: 429-433.

26. Rohde LE, Hennekens CH, Ridker PM (1999) Survey of C-reactive protein and cardiovascular risk factors in apparently healthy men. Am J Cardiol 84: 1018-1022.

27. Sesso HD, Bruing JE, Rifai N, Blake GJ, Gaziano JM, et al. (2003) Creactive protein and the risk of developing hypertension. JAMA 290: 2945-2951.

28. Bermudez EA, Rifai N, Buring J, Manson JE, Ridker PM (2002) Interrelationships among circulating interleukin-6, C-reactive protein, and traditional cardiovascular risk factors in women. Arterioscler Thromb Vasc Biol 22: 1668-1673.

29. Shafi Dar M, Pandith V, Sameer AS, Sultan M, Yousuf A, et al. (2010) hsCRP a potential marker for hypertension in Kashmiri population. Indian J Clin Biochem 25: 208-212.

30. King DE, Egan BM, Mainous AG, Geesey ME (2004) Elevation of Creactive protein in people with prehypertension. J Clin Hypertens 6: $562-568$

31. Wofford MR, Hall JE (2004) Pathophysiology and treatment of obesity hypertension. Curr Pharm Des 10: 3621-3637. 